\title{
Phenotypic determination of noise reactivity in 3 breeds of working dogs: a cautionary tale of age, breed, behavioral assessment and genetics
}

\author{
Karen L. Overall ${ }^{1 *}$, Arthur E. Dunham ${ }^{1}$, Soraya V. Juarbe-Diaz ${ }^{2}$ \\ ${ }^{1}$ Biology Department, University of Pennsylvania, Philadelphia, PA, 19104 USA \\ ${ }^{2}$ Affiliated Veterinary Specialists, Maitland, FL, 32751, USA \\ *Corresponding author: overall.karen@gmail.com
}

\section{Abstract:}

Noise reactivity is a common problem for dogs, and may progress to true phobia. Survey studies report that some type of noise reaction occurs in up to half of all pet dogs throughout their lifetimes, indicating that noise reactivity/phobia is a welfare issue. Familial aggregations of affected dogs have been reported and increased prevalence in certain breeds has been suggested. Reactivity to noise can severely compromise function in both pet and working dogs. Noise reactivity may be co-morbid with many anxiety disorders for both canines and humans and is postulated to effect information processing in associated human, rodent and dog conditions. Any putative effect of noise on information processing becomes a concern for problem solving and other aspects of cognition that are important to working dogs. Accordingly, we sought to phenotype 3 breeds of herding dogs commonly used for work as detection dogs, police/patrol dogs, search and rescue dogs, and/or service dogs: Australian shepherds (AUS), Border collies (BOC) and German shepherds (GSD). We analyzed demographic information and behavioral responses to noises (guns, storms, fireworks) known to provoke fearful or phobic responses for 59 AUS, 81 BOC, and 58 GSD, who were also included in a genetic analysis. Behaviors were compared using a metric constructed from information on type, frequency and intensity of response, the Anxiety Intensity Rank (AIR score). Reactivity to noise was found to segregate in some family lines for the dogs in this study, although individuals expressed considerable variation in noise response. Such variation may be time and exposure dependent and presents a phenotyping challenge. In this study, the presence and intensity of reactivity as represented by AIR scores varied by breed, but only slightly with age. The BOC studied were older, and BOC and AUS were more severely affected (higher AIR scores) than were GSD. Source/purpose of dog may also affect severity of affliction. Determination of crisp, accurate phenotypes is essential for understanding underlying genetic contributions. For noise reactivity/phobia accurate phenotypes include age of onset and specific behavioral characterization. Standardized, objective assessments are essential for assessment of progression and co-morbidity. Our data imply that accurate phenotypic assessment is possible at a relatively early age, providing for both humane treatment and accurate phenotyping that facilitates good genotyping.

Keywords:

Dog, noise phobia, noise reactivity, phenotype, genotype, Border collie, Australian shepherd, German shepherd, working dog

Introduction:

Noise reactivity and phobia are common pathological behavioral conditions in pet dogs. Many surveys report that up to $50 \%$ of dogs may be affected by some extreme reaction to some noise during their lifetime (Blackshaw et al., 1990; Dale et al., 2010; Blackwell et al., 2014; Storengen and Lingaas, 2015; Tiira and Lohi, 2015, 2016). Reactions are most commonly reported for storms, fireworks and guns, but noises associated with vehicles, machines, alarms, et cetera can also trigger fearful, anxious or phobic responses in dogs (McCobb et al., 2001; King et al., 2003; Ley et al., 2007). 
A number of other terms are often used to describe an adverse reactive, fearful or phobic response, including noise aversion, noise fear, noise stress, storm or thunderstorm phobia and noise sensitivity. Necessary and sufficient criteria for labeling a dog 'noise reactive' or 'phobic' or any of these other terms are usually not usually included in most studies (but see Overall et al., 2001 and Dreschel and Granger, 2005), nor are the range of behaviors potentially displayed by the afflicted dog often noted (but see Overall et al., 2001; Crowell-Davis et al., 2003; Overall et al., 2010; Tiira and Lohi, 2014; Tiira et al., 2016). Without standardized, discrete diagnostic criteria and unbiased, quantifiable behavioral assays for such criteria, we greatly diminish the possibility of understanding and identifying true familial, breed and population associations for any behaviors that are problematic for dogs because we cannot recognize dogs that are more similar or dissimilar (Overall, 2005; Overall et al., 2014; Tiira and Lohi, 2014; van Rooy et al., 2014).

Diagnostic criteria also permit discrimination of behavior patterns that are a manifestation of normal behavior from those displayed as a manifestation of abnormal and pathological behavior. Some response to an acute stressor is normal and adaptive, and such responses are characterized by recovery with a return to the individual's baseline of behavior. Pathological responses include those that are out of context to the stimulus where signs of acute stress are excessive in duration and/or intensity and become more so with each exposure until an extreme plateau is reached. Spontaneous recovery is absent in pathological responses. This distinction between normal and abnormal or pathological is essential since the misinterpretation of canine behavior by humans is common (Haverbeke et al., 2009; Tami and Gallagher, 2009; Kuhne et al., 2012a,b; Wan et al., 2012; Bloom and Friedman, 2013; Kuhne et al., 2014; Foyer et al., 2015), and owners do not recognize subtle signs of anxiety (Mariti et al., 2012). An owner judgment about undefined 'anxiety', 'fear' and 'aggression' in a survey questionnaire, especially one using a Likert scale (Serpell and Hsu, 2001; Temesi et al., 2014), is impossible to validate (Diederich and Giffoy, 2006; van Rooy et al., 2014) and is void of information pertaining to behavioral heterogeneity that can allow us to study mechanism.

We propose that it is possible to create objective assessments of behavior that are void of judgment and that use clear terminology (Overall et al., 2001; Crowell-Davis et al., 2003; Overall et al., 2006; Tiira et al., 2014). It is possible to identify observable criteria associated with the dog's indication that he is reacting to a stressor (here, noise) and to evaluate those criteria in terms of intensity, frequency, duration and specific response, as we have done here. Assessment of phenotypes can only elucidate genetic studies if the behavioral criteria used are clear, crisp, and accurately reflect and discriminate among the behaviors exhibited by the dogs.

The diagnostic criteria used here were validated in a clinical study of noise phobia (Overall et al., 2001), and require that noise phobic dogs exhibit a profound, non-graded, extreme response to noise manifest as intense avoidance, escape, or anxiety and associated. Such signs are associated with the sympathetic branch of the autonomic nervous system, and triggered by reactivity in the locus ceruleus (LeDoux, 2000; Tully and Bolshakov, 2010). Dogs who are characteristically distressed when exposed to specified noises, including storms, but who do not meet the criteria for a 'phobia' may be classified as 'reactive' (Overall, 2013). We chose the term 'reactive' rather than 'sensitive' (Sherman and Mills, 2008; Tiira et al., 2016) because 'sensitive' may imply, could be confounded with and is commonly used to describe attributes of auditory capability, for which we have no data. The term 'reactive' implies no underlying mechanism, merely a lowering of threshold.

The behavioral signs of distress associated with noise reactivity and phobia are non-specific but can be 
benchmarked and quantified. These signs may include trembling, freezing, panting, social withdrawal, pacing, salivating, urinating, defecating, destruction (with or without self-injury), hiding/crouching (includes body lowering and tail tuck postures) and escape/running away behaviors (with or without self injury) (Schull-Selcer and Stagg, 1991; Beerda et al., 1997, 1998; Overall et al., 2001; Crowell-Davis et al., 2003; Hydbring-Sandberg et al., 2004; Sherman and Mills, 2008; Overall et al., 2010; Cracknell and Mills, 2011), which are all classic responses to anxious states and represent an acute stress response. These are all signs of anxiety that owners can recognize and use to tell when their dog is distressed (Mariti et al., 2012).

Dogs exhibiting these anxious and panicky signs in response to a noise stimulus experience both physical and behavioral debility and compromise (Dykman et al., 1966; Murphree et al., 1967; Overall et al., 2001; Dreschel and Granger, 2005; Dreschel, 2010; Siniscalchi et al., 2014). Noise reactivity and phobia interferes with performance in working dogs (Tomkins et al., 2006, 2007; Gazzano et al., 2007; Batt et al., 2008; Asher et al., 2013; Arvelius et al., 2014; Sherman et al., 2014; Evans et al., 2015) and interferes routine patterns of daily life in pet dogs (Overall et al., 2001). Noise reactivity and phobia is associated with patterns of brain organization (Branson and Rogers, 2006; Siniscalchi et al., 2008), which may be one mechanism through which pathological changes occur.

Similar patterns pertain in other species. In rats, performance in maze tests (number of errors, time to goal, and number of rearings) was impaired when the rats were exposed to loud noise (100dB-BGN, the low end of noise estimates for the stimuli in this study; http://www.noisehelp.com/noise-levelchart.html ), and neurons in the hypothalamic paraventricular nucleus, central nucleus and basolateral nucleus of the amygdala, regions associated with stress, were activated (Ameniya et al., 2010). Chronic and acute noise stresses produced differential responses in the hippocampus, but similar responses in the hypothalamus, suggesting that behavioral effects can be influenced by exposure (Eraslan et al., 2015). Noise stress (105 dB) has been shown to impair higher order, pre-frontal cortex, delayedresponse performance in cognitive trials in monkeys (Arnsten and Goldman-Rakic, 1998). Babisch (2003) noted that noise activates sympathetic responses and stimulates epinephrine, norepinephrine and cortisol, all hormones associated with stress. Acute noise stress in humans has been shown to impair cognitive control in the anterior cingulate cortex (Banis and Lorist, 2012).

Pathological noise reactions in dogs worsen quickly with exposure, suggesting that adverse effects on mental and physical health are long-term and may be more profound than usually appreciated. Many of these reactions may be modulated by changes in glucocorticoid receptor regional activity and subsequent molecular processes which adversely affect both cognitive ability and retrieval and use of memory (Popoli et al., 2011; Nasca et al., 2015; Jasnow et al., 2016; Rogerson et al., 2016). Noise phobia is considered a commonly co-morbid condition (, affecting both general fears (Tiira and Lohi, 2015) and specific conditions like separation anxiety (Overall et al., 2001). When noise phobia is co-morbid, the signs of each condition are worse than for canine patients with a single anxiety-related condition (Overall et al., 2001), suggesting that the noise pathology, itself, changes the underlying neurochemical or neuronal reactivity. Co-morbid conditions in humans and other primates show similar patterns of effect where signaling in the amygdala, hippocampus and frontal cortex can be impair in response to repeated stress signaling (Arnsten et al., 1998, 2009).

Materials and methods:

Dogs of the 3 breeds studied (59 Australian shepherds (AUS), 81 Border collies (BOC) and 58 German shepherds (GSD)) were solicited from breed clubs during working dog trials at breed club shows. For the all of the dogs trials involved herding and/or obedience and for the GSD, many also were involved in 
Schutzhund (protection sport training and competition). All of the AUS and BOC were solicited and sampled in the USA, although more than half of the BOC were from European origin or lines. About half of the GSD were solicited and sampled at a GSD show in Holland, and the overwhelming majority of the rest were detection dogs from various US government contractors. These dogs all likely originated in Europe, although we could not confirm country of origin for all dogs from the contractor records, and pedigrees were unreliable.

Owners of the dogs were asked to complete a short questionnaire (Overall et al., 2001; 2006: see supplemental materials for questionnaire version used) that included demographic questions and that asked whether the dogs reacted to:

(1) storms/thunderstorms,

(2) gunshots,

(3) fireworks and

(4) other noises.

If the owners/handlers noted that their dog responded to 'other noises', they were asked to specify the noise and to describe the reaction since not all reactions to all noises are associated with pathology (e.g., dogs who chased or played with vacuum cleaners were not considered 'phobic', but those who hid in response to the noise of the vacuum were considered 'phobic'). These stimuli are likely not all perceived the same way for dogs. Storms have visual, auditory, barometric and other atmospheric components (wind, rain), whereas the sound of a gunshot depends on the weapon and the sound of fireworks depends on the pattern or the display and chemical formulation. Fireworks also have a visual component present for many but not all storms and absent for most guns. For the purposes of this study we investigated the reaction to the situation, not individual stimuli (although see Scheifele et al., 2016).

Choices for each of the noise categories were: (1) Yes, (2) No or (3) Unknown. If the owners chose 'yes', they were asked to estimate with what frequency to the noise the dog reacted:

- $100 \%$ of the time,

- $<100 \%$ but $>60 \%$ of the time,

- $40-60 \%$ of the time,

- $>0 \%$ but $<40 \%$ of the time.

Because frequency of reaction may not be independent of frequency of occurrence of the noise stimulus, clients were also asked how often the dog was exposed to each of the noises. Choices were: 'never', 'occasionally/a few times per year', 'regularly/about once a month or so', 'frequently/a few times a month or more in some seasons'. This question ensured we were studying dogs for whom adequate information was available. For the purposes of the analysis, only dogs who experienced the noise 'regularly/about once a month or so' or 'frequently/a few times a month or more in some seasons' were included, but these were the vast majority of the dogs belonging to owners who decided to participate.

For each noise to which the dog reacted, clients were asked to specify the type(s) of response: salivate, defecate, tremble, urinate, vocalize, destroy, pace, escape, freeze, pant, and/or hide (which included crouching - the photo used in the solicitation showed an Australian shepherd crouched in a bathtub and a Border collie hiding in a crate; see Figure 1). Not all owners will notice all signs equally (Mariti et al., 2012), so there may be some false negatives in our data set, but false positives are minimized because there is no mistaking these signs if the dog exhibits them when exposed to the triggering noise. 
All dogs had a $5 \mathrm{ml}$ cephalic vein blood sample taken using a 21 gauge butterfly catheter. Samples were chilled and sent overnight on ice for later genetic analysis. Preliminary genetic analyses were conducted using Affymetrix arrays (see Yokoyama, 2010 for specific details). Pedigrees were requested for all dogs.

Questionnaires were reviewed by the researchers with the owners on site for completion, errors and understanding. Owners were encouraged to ask questions so that they understood the importance of the information they were providing. For the Dutch dogs, questionnaires were provided in both English and Dutch and the Dutch questionnaire was both forward and reverse translated. Additionally, a native Dutch speaker aided in the solicitation of the owners and in the review of the questionnaires with both the owner and the researcher. The native Dutch speaker also helped with the discussion of the study and the dog's behaviors between the owner and researcher, if needed.

Data were entered into a Filemaker Pro database. AIR scores were calculated by multiplying the number of signs any dog showed by a weight determined by frequency of reaction, with the frequencies above receiving a weight of 4, 2.5, 1.5, 1 and 0 , respectively, and summed for all provocative stimuli (Overall et al., 2010; Overall, 2013). AIR scores can be calculated for a single inciting stimulus, a discrete subset of stimuli, or for a sum of all AIR scores from all trigger stimuli (global AIR score). As reported here, the AIR score refers to the sum of scores across all stimuli (i.e., global AIR score). The total score possible for the 3 main stimuli if all signs were evident all of the time is 132 . This extreme score represents an upper bound and would be exceptional since dogs would have to exhibit both freezing and pacing, which is possible, but appears to be rarely reported.

Data were subjected to routine parametric, where appropriate, and non-parametric analyses using $R$ ( $R$ Core Team, 2016). The phenotyping results for dogs of each breed for which preliminary genome wide association (GWA) analysis data were available are discussed here.

All aspects of this study were approved by the University of Pennsylvania's Institutional Animal Care and Use Committee (IACUC) as required by US law. Additional approvals we obtained from the funding agencies' IACUCs. All participating owners signed an informed consent statement.

Results:

Only dogs who experienced noise 'regularly/about once a month or so' or 'frequently/a few times a month or more in some seasons' were included in this study. No one reported that their dog was 'never' exposed to noises.

The majority of owners/handlers participating in this study indicated that their dog never reacted to noises, although fewer BOC (26/81) than AUS (32/59) and GSD (42/58) were reported to not react. Of those who reported the various behavioral reactions to noise stimuli, the majority of AUS and BOC owners reported that the dog always reacts, regardless of noise stimulus, but more AUS were reported to react $<100 \%$ but $>60 \%$ of the time. Owners/handlers of GSD most commonly reported that dogs react $<60 \%$, but $>40 \%$ of the time for all stimuli, a different presentation than for the other breeds (Figure 2) (all comparisons, $\mathrm{P}<0.0001$ ).

Mean ages of dogs in this study were 58.00 months for AUS (N=59), 79.95 for BOC $(N=81)$ and 42.85 $(\mathrm{N}=58)$ for GSD (Table 1; Figure 3). In this study BOC were older than AUS and both AUS and BOC were older than GSD. This pattern was reflected in both those dogs reported to react and those dogs who did not react to noise. As reflected by the age distribution, young and immature dogs were a small part of 
this study population: no GSD, 2 BOC and 4 AUS were 10 months of age or younger (Figure 3). Puppies and immature dogs are not common at trials where these dogs were solicited. Our first large pulse of dogs with noise reactivity/phobia for all breeds occurred at 20 months, concomitant with social maturity.

The non-zero global AIR score data (e.g., affected dogs, only) were 18.02 for AUS ( $N=27$; range: 1-64), 25.25 for $\mathrm{BOC}(\mathrm{N}=55$; range: $1-84$ ) and 6.13 for GSD ( $\mathrm{N}=16$; range: $1.5-16)$ (Table 2). The mean AIR scores for AUS and BOC are not significantly different, but both differ significantly from those of GSD, which are considerably lower. In the dogs studied here, GSD are less affected by noise reactivity than are AUS and BOC (AUS x BOC, ns, p=0.322; F-test; AUS x GSD \& BOC X GSD, p=0.00001; F-test).

No regression of AIR scores on age for any breed was significant except for that of GSD (Figure 4). The linear regressions of AIR score on age for affected dogs of each breed were as follow; AUS: $F=1.315$, df $=1,25, P>0.262, r^{2}$ adj $=0.12 ;$ BOC: $F=1.387, d f=1,47, P>0.244, r^{2}$ adj $=0.008 ; G S D: F=11.69, d f=1,13$, $P<0.005, r^{2}$ adj $=0.433$. In this study older GSDs had lower scores than younger dogs.

There are no significant regressions for any breed when comparing age with number of signs shown by the dogs under any stimulus condition (Figure 5$)$. For AUS: thunderstorms: $(F=0.184, d f=1,17, P>$ 0.67), fireworks: $(\mathrm{F}=0.850, \mathrm{df}=1,19, P>0.369)$, gunshots: $(\mathrm{F}=0.203, \mathrm{df}=1,9, P>0.66)$. For $\mathrm{BOC}$ : thunderstorms: $(\mathrm{F}=4.01, \mathrm{df}=1,44, P>0.051)$, fireworks: $(\mathrm{F}=0.748, \mathrm{df}=1,40, P>0.392)$, gunshots: $(\mathrm{F}$ $=0.064, \mathrm{df}=1,30, P>0.80)$. Regression analysis on the German shepherd data cannot be done due to lack of variation in the dependent variable. This finding suggests that the condition of noise phobia/reactivity was fully developed in the dogs in this study. The average age of any breed in our study was greater than 40 months.

For none of the breeds in this study was co-occurrence of signs independent, regardless of type of provocative stimulus (Spearman rank correlation analysis with all $\mathrm{P}<0.01$; Table 3 ), suggesting that true co-morbidity may be occurring. Our data show that (a) reactions for all breeds are not general noise responses, but responses to specific stimuli and (b) reactions to different stimuli are highly co-morbid. Pairwise permutation tests indicate all conditional probabilities are significantly greater than 0.7 or higher with all $P<0.001$ ) (Table 4).

Breeds from the populations used in this study differ in the signs and frequencies of signs that they show within and across provocative stimuli (Figure 6). In this study GSD differed from AUS and BOC, 2 breeds which have GSD in their genetic ancestry (vonHoldt et al., 2010). Pairwise permutation tests indicate that the distribution of signs for GSD differ significantly from those of both AUS $(P<0.0001)$ and $B O C(P<0.0001)$. The distribution of signs of AUS and BOC do not differ significantly from each other ( $P$ $>0.45$ ). Regardless of stimulus, GSD in this study paced, whereas BOC and AUS reacted by hiding and panting in a relatively constant way across stimuli. GSD in this study were never reported to salivate, escape, tremble or freeze.

A GWA analysis revealed areas of interest on chromosomes 5, 8 and 10. No findings reached genome wide significance (Yokoyama, 2010). Treating these dogs as affected (dogs reacted $>/=60 \%$ of the time) or not and expanding the number of dogs genotyped (BOC 189; AUS 119; GSD 93) allowed a populationbased case-control comparison of BOC, AUS and GSD and yielded some potential regions of interest on chromosomes 7, 10, 12, 23, 25 and 28. The strongest finding in the case-control comparison for an expanded subset of data was for chromosome 12 in an intron of the KLHL32 gene, which was the top finding in the BC only analysis, the combined BC $\times$ AUS and BC X AUS X GSD analyses $\left(2 \times 10^{-06}\right.$, odds ratio: $0.07,95 \%$ confidence intervals, $0.02-0.24$ ) (Overall and Hamilton, unpublished, DARPA report). 
Examination of population substructure revealed an average heterozygosity for AUS of 0.424 (SD= 0.019), greater than that for $B O C$, which was 0.407 ( $S D=0.007$ ) (Yokoyama, 2010). The SD for AUS was nearly 3 times that of $B O C$, suggesting that the $B O C$ we studied were less variable. The underlying genetic substructure between BOC and AUS is shown in Figure 7. A pedigree for one of the BOC families in this study is shown in Figure 8.

\section{Discussion:}

One of the challenges for phenotyping behaviors in dogs and of canine behavioral genetic studies, in general, is enrollment of a suitable number of dogs. The data presented here focus on 59 AUS, 81 BOC, and $58 \mathrm{GSD}$ recruited over an 8 month period at trials and included in a GWA analysis. Over the course of 1.5 years, 189 BOC, 119 AUS and 93 GSD were recruited, but the putative polygenic nature of most behavioral conditions requires even larger numbers of unrelated dogs (van Rooy et al., 2014). It is possible to recruit the appropriate dogs and engage in the type of due diligence required to view the dogs and discuss them with each owner, but the process is viewed as labor intensive and expensive.

All dogs in this study on noise reactivity/phobia were exposed to the main classes of noises discussed (storms, fireworks, gunshots) sufficiently often for owners to comment in an informed manner on whether the dogs were reactive/phobic. While not all of the signs of noise reactivity/phobia are equally obvious to all owners, all have been noted in clinical patients in various studies (Overall et al., 2001; Crowell-Davis et al., 2003; Cracknell and Mills, 2011). With the exception of one contractor who provided dogs, participating groups and individuals appeared extremely knowledgeable about and interested in their dogs.

The majority of AUS and GSD were reported to not react to exposure to these noises. Dogs for this study were solicited at trials, which may be one reason why so many of these dogs were unaffected. While one might expect that dogs at trials are less seldom affected with behavioral conditions than are dogs in the population as a whole, this may not be the case. We do not know which owners are willing to share behavioral information with researchers and without knowing this, no assumptions should be made. It is possible that people from trialing populations are happy to share information about their dogs when the dogs are unaffected by behavioral problems, but are less willing to do so if their dogs are affected. We lack good prevalence data for this and all other conditions in behavioral medicine, and it is a problem.

Breeders, trainers and owners may feel a stigma about behavioral pathologies. Owners seeking the help of specialists in behavioral medicine often report that they feel that they have contributed to the problem or feel guilty or responsible for some aspect of it, so it is possible others feel similarly. This unfortunate and usually incorrect attitude adversely affects studies like ours, but it also prevents dogs from getting needed and available specialist and researcher help in a timely manner. As a result, breeding of dogs and genetic lines that may be at enhanced risk for behavioral pathology continues without the benefit of genetic and behavioral counseling. While dogs with behavioral conditions are excellent natural animal models for human psychiatric illnesses (Overall, 2000; Overall et al., 2001; Overall and Dunham, 2002; Dodman et al., 2010, 2016; Ogata et al., 2013; Cao et al., 2014), breed and individual health is primary and is improved by establishing and participating in such studies ( $O^{\prime}$ Neill et al., 2014; Overall et al., 2014; van Rooy et al., 2014).

Unfortunately, there are no population-wide epidemiological data in this field that could allow us to learn whether participation tracks incidence or true prevalence, although Tiira et al. (2016) provide some survey data. Our study provides some of the first age- and breed-associated incidence data available not solely from long-distance surveys, and it is an inadequate base for conclusions other than 
those which are conservative. The lack of comparable, validated behavioral data across populations in the fields of canine behavior and canine behavioral medicine has been and remains an impediment to progress (Overall et al., 2014; van Rooy et al., 2014). In no small part, this deficiency is due to lack of standardized terminology, lack of validated assessment tools and lack of validated ethograms (Overall, 2013, 2014; Overall et al., 2006, 2014; van Rooy et al., 2014; O'Neill and Packer, 2016, Stone et al., 2016). An understanding of underlying mechanism for any behavior - normal or pathological - at any level, including the genetic one, requires a rule to cluster increasingly more similar patterns in groups separate from those which are increasingly less similar, in a manner that acknowledges the role of context and that will facilitate objective tests of underlying mechanism (Overall, 2005).

Both the ages of dogs in this study and the lack of any significant regression of AIR scores on age for BOC and AUS supports that the condition was fully developed by the time these dogs were assessed, and that young and immature dogs were not a large part of this study population. As noted, our first large pulse of dogs with noise reactivity/phobia for all breeds occurred at 20 months, concomitant with social maturity. The implication is that by 20 months of age noise reactivity/phobia is fully developed. Social maturity, when neurochemical liability is thought to develop or become characteristic as has been suggested in rodents and humans (see Kerestes et al., 2014 for an review of imaging studies; Whittaker et al., 2016), appears to occur between $\sim 10$ and 36 months, with the most common manifestations being apparent at 12-18 months (Overall, 2013), the time when behavioral tests become reliable (Asher et al., 2013; Foyer et al., 2014; Evans et al., 2015; Harvey et al., 2015; 2016). That GSD who were older had lower AIR scores than those who were younger may suggest that as dogs age, those GSD who react to noise were excluded from the trialing population. Given the source of our GSD and the testing to which they are exposed, this hypothesis may have merit. These GSD may have come from more than one population of European dogs.

It is important to remember that our data are a snapshot in time. No dogs were followed through time so no time-penetrant developmental patterns should be assumed, although they are reported in clinical populations (Overall et al., 2001; Crowell-Davis et al., 2003; Dreschel, 2010; Overall, 2013). Regardless, this study strongly supports the published recommendation and need for frequent (at least 3), pre-social maturity veterinary evaluations of all dogs, with routine behavioral screening, including for reactions to noise (Hammerle et al., 2015). Relatively short questionnaires that can be used at each visit to track development of behavioral pathologies, including noise reactivity/phobia, are in the public domain (Overall, 2013).

The mean AIR scores for AUS and BOC did not differ from each other but both differed from those of GSD, which also displayed different reactive behaviors when exposed to noise. Regardless of stimulus, GSD in this study most commonly paced, whereas BOC and AUS reacted by hiding and panting in a relatively constant way across stimuli. All 3 of these signs were reported in more than $50 \%$ of dogs of various breeds enrolled in a clinical study which found that $94 \%$ of the afflicted dogs exhibiting panting, $88 \%$ exhibiting trembling, $88 \%$ becoming clingy or seeking atypical closeness, $86 \%$ pacing, and $81 \%$ hiding (Crowell-Davis et al., 2003). These breed associated behavioral differences are important difference since in rats, crouching behaviors may be indicators of fear (Blanchard and Blanchard, 1969), and increasing numbers of canine studies are using lowered body postures as similar indicators (Schilder and van der Borg, 2004; Haverbeke et al., 2008; De Meester et al., 2011; Tiira et al., 2016).

In the present study, GSD were never reported to salivate, escape, tremble or freeze, signs commonly reported in both clinical (Overall et al., 2001) and non-clinical (Tiira et al., 2016) studies. It's tempting to make an argument about shared breed derivations (VonHoldt et al., 2010), but only a subset of the dogs 
in this study (BOC>AUS>GSD) were severely affected by exposure to noises that triggered their distress and none of the GSD were. No dogs in this study urinated, defecated or destroyed, non-specific signs routinely reported in clinical noise phobic patients (Overall et al., 2001; Crowell-Davis et al., 2003). The lack of reports of salivating, escaping, trembling and freezing for GSD in this study suggested that the GSDs surveyed were mildly affected, a conclusion supported by AIR score patterns. In clinical situations, GSD are reported to exhibit the range of behaviors associated with greater distress. It is possible that there are multiple sub-populations of dogs within any breed that react to noise in different ways for a given stimulus. If so, this would suggest underlying population genetic and mechanistic variability.

Knowledge of non-specific signs exhibited is essential for behavioral genetics studies. Our data suggest that while breeds appear to share genetic regions that likely increase their liability risk for noise reactivity/phobia, there are also heritable differences within breeds that affect the manifestation of the reactivity (e.g., specific behavioral response) within that breed. Indeed, different regions of the brain, in general, and the amygdala, specifically, affect the behaviors exhibited by noise reactive/phobic AUS and BOC compared with GSD (Davis, 1997). Accordingly, noise reactivity/phobia is likely a polygenic condition or set of conditions, a conclusion supported by our preliminary genetic results. Large numbers of affected dogs are needed to define the phenotypes and genetic basis of such conditions, although new sequencing methodologies make extremely effective use of data from stratified populations (van Rooy et al., 2014).

The breed pattern of the behavioral responses is likely important for determination of a phenotype. Diagnoses are not phenotypes, but when carefully defined using restrictive criteria and noting specific patterns of behaviors they may group dogs together in ways that ensure that they are more similar than less, diagnoses can inform phenotypes (Overall, 2000; Overall, 2005; Overall et al., 2010) and allow breeds to be compared. Overall and Dunham (2002) noted that breed influenced the specific manifestation of canine obsessive-compulsive behaviors (OCD) in one clinical study. This observation has been made by others, and different breed groups are associated with different OCD manifestations. Bull terriers and Staffordshire terriers spin and tail chase (Moon-Fanelli et al., 1998; Tiira et al., 2012), GSD chase their tails (Overall and Dunham, 2002; Tiira et al., 2012) and Doberman pinschers flank and fabric suck (Moon-Fanelli et al., 2007; Dodman et al., 2010; 2016). It is entirely possible that in the course of selecting for breed-related behaviors or physical manifestations we have inadvertently selected for covarying liability genes. It is also possible that by selecting for some attribute, an extreme variant of some behavioral association was selected for and expression varied depending on the dog's environment (Tiira et al., 2012) or utility, resulting in a series of liability genes contributing to various behavioral expressions. Cao et al. (2014) proposed the latter process for Belgian malinois, where circling and tail chasing is frequently seen in working dogs, resulting in balancing selection for a genomic block of the $\mathrm{CDH} 2$ gene. It is possible that a similar process has occurred for noise reactivity/phobias in any of these breeds, were one to select for some degree of heightened responsivity. The risk may be higher for BOC since owners of dogs in this study reported that many of their affected dogs could or were forced to work throughout their reactions to noise.

A GWA analysis for the dogs reported here revealed areas of interest on chromosomes 5,8 and 10, but none of our findings reached genome wide significance. While our data were largely distributed in a way that could support a case-control analysis (reacts $0 \%$ of the time v. $60 \%$ plus, a more conservative standard than Tiira et al., 2016), liability for noise reactivity/phobia varies considerably and is likely polygenic, as suggested by the breed differences noted here. Examination of population substructure revealed an average heterozygosity for AUS that was greater than that for BOC, and a SD for heterozygosity for AUS that was nearly 3 times that of BOC. This lower heterozygosity may also play a 
role in the extent to which $\mathrm{BOC}$ were affected with noise reactivity/phobia since there is a likelihood that some risk liability genes may be identical by descent.

Our study demonstrates that noise reactivity/phobia - which is only one clinical type of pathological fear - does not have one manifestation. Fear has long been treated in the canine heritability and genetic literature as a unitary condition. It is not, and an approach to phenotypes that encompasses context and specific behavior is long overdue (Overall, 2005). Regardless, it would be unusual were these varied manifestations not driven by different genes since they represent different system responses and different brain regions (LeDoux, 1988; Davis, 1997). The ability of breed to inform such differences adds another layer of complexity to mechanisms that may be important.

Number and intensity of signs may also suggest that different phenotypes of any condition may be driven by different mechanisms. The importance of such patterns has become apparent in the evolving research on flank sucking in Doberman pinschers. Dobermans with flank and blanket sucking expressed a higher frequency of an allele in the $\mathrm{N}$-cadherin/CDH2 gene on chromosome 7 (CFA 7) than did unaffected dogs (Dodman et al., 2010). Number and intensity of signs may be reflected in ancillary gene frequencies (Dodman et al., 2016). Brains of affected dogs also differed with affected dogs showing higher total brain and grey matter volumes in lower dorsal anterior cingulate cortex and right anterior insula gray matter density (Ogata et al., 2013). Interestingly, the fractional changes in corpus callosum communication correlated with the severity of the condition. Other studies have shown lower $5-\mathrm{HT}_{2 \mathrm{~A}}$ receptor binding in the frontal and temporal cortex of dogs with OCD (Vermeire et al., 2012), but it is not known whether levels vary with severity. Number and intensity of signs are likely relevant for both phenotyping and genotyping since severity of condition of OCD has been reported to correlate with treatment success in both dogs (Overall and Dunham, 2002) and humans (Haghihi et al., 2013).

It should be noted that what made it possible to obtain Doberman pinschers in sufficient numbers to phenotype and genotype were the very patterns that we have discussed earlier, which are not the norm for most behavioral conditions: the behavior was easily recognizable by owners and could not be mistaken for anything else, the behavior was widespread in family lines in a breed with other, historical interests in genetic health, the behavior does not occur in other breeds, the dogs either engaged in the behavior or did not, and time penetrance may have affected the severity of the condition (number and intensity of signs) (Dodman et al., 2016). If the latter is reflected in ancillary gene frequencies, the patterns of how pathologies may develop become an important consideration for phenotype. Additionally, in contrast to the situation for noise reactivity/phobia, flank sucking behavior in Dobermans is not injurious to the dog and so no blame could be attendant with owner or breeder practices, a situation appealing to dog fanciers. The time has come for owners and breeders to work closely with behavioral medicine specialists and researchers so that we can uncover important phenotypes and their underlying genetic risks and mechanisms.

Our data suggest that true co-morbidity of responses to multiple stimuli is occurring, and that it may worsen the presentation of the behavioral condition studied here, noise reactivity and phobia. Furthermore, reactions for all 3 breeds that we studied are not general noise responses, but responses to specific stimuli. That reactions to the classes of noise stimuli studied are most highly co-morbid in the breed with the highest global AIR scores (BOC) and less co-morbid in the breed with the lowest global AIR scores (GSD) may be important and have considerable implications for mechanism. A similar pattern was reported for a general patient population of dogs affected with co-morbid separation anxiety and noise reactivity/phobia (Overall et al., 2001). In that clinical population, dogs who reacted to storms, which were more unpredictable in time and characterization than other noises to which the 
patients were reported to react, were more likely to react to other noises (conditional probability of reacting to other noises given that you react to storms $=0.8974$ ), than when the pattern was reversed (conditional probability of reacting to storms given that you reacted to other noises $=0.7609$ ). Lack of control and unpredictability are often associated with stress responses, including those related to noise. Breier et al. (1987) similarly found that stress associated with unpredictable noise was associated with more pronounced behavioral and hormonal responses in humans.

Whether the co-morbidity between noise responses and triggers is due to shared neurochemical mechanisms or changes in underlying neurochemical substrate caused by 1 stimulus is not known, but may be important. For owners who need to treat the distress experienced by these dogs, knowledge that these conditions are likely to be co-morbid, that the condition is time penetrant and that the number of signs exhibited matters is essential, especially in light of cognitive effects, if treatment is to be successful (Overall et al., 2001; Tiira et al., 2016).

Conclusion:

Our data show that clear definitional criteria and specific behavioral evaluations lead to crisp phenotypes that permit further epidemiological and mechanistic investigations. Furthermore, breed may inform phenotype, emphasizing the importance of determining the epidemiology and discrete pattern of behavioral responses. The mental health and welfare of dogs benefits from such approaches.

Acknowledgments:

We thank the breeders, fanciers and owners who helped with this study, especially the Australian Shepherd Club of America (special thanks to C.A. Sharp), the Border Collie Club of America and the Dutch German Shepherd Kennel Club. Jan Zoodsma facilitated the work with the latter and helped in The Netherlands with data and blood sample collection. Adee Schoon and Jan Zoodsman translated the questionnaire. This study was funded by a DARPA (Defense Advance Research Projects Agency) grant DARPA FY06-0028 / 52731-LS-DRP to KLO. The writing of this paper was funded by DoD ARO grants W911NF-14-1-0574 565053 and 65366-LS to KLO and AED. The authors wish to thank the reviewer who provided such helpful comments.

Conflict of interest statement:

Parts of this paper were presented at the Canine Behaviour and Genetics meeting in London, UK, in June 2015. Dr. Overall is the Editor-in-Chief of the Journal of Veterinary Behavior: Clinical Applications and Research. A guest editor was appointed for this special volume. This study was conceived by Karen Overall and Art Dunham. The study was conducted by Karen Overall, Art Dunham and Soraya V. JuarbeDiaz with technical help from Donna Dyer, and support from Melanie Chang and Jennifer Yokoyama from Steve Hamilton's lab at UCSF. All parts of the study, including the GWA analysis, were funded by Karen Overall. The genetic analyses were performed by Melanie Chang (who was a post-doc paid by the grant) and Jennifer Yokoyama. Soraya Juarbe-Diaz created the AIR score system. The statistical analysis was performed by Art Dunham. All authors contributed to the writing of the paper.

References:

Amemiya, S., Yanagita, S., Suzuki, S., Kubota, N., Motoki, C., Otsuka, T., Nishijima, T., Kita., I., 2010.

Differential effects of background noise of various intensities on neuronal activation

associated with arousal and stress response in a maze task. Physiol. Behav. 99, 521-528. 
Arnsten, A.F,T., Goldman-Rakic, P.S., 1998. Noise stress impairs prefrontal cortical cognitive function in monkeys. Evidence for a hyperdopamine. Arch. Gen. Psychiatry 55, 362-368.

Arnsten A. (2009) Stress signalling pathways that impair prefrontal cortex structure and function. Nat Rev Neurosci. 2009 June ; 10(6): 410-422. doi:10.1038/nrn2648.

Arvelius, P., Asp, H.E., Fikse, W.F., Strandberg, E., Nilsson, K., 2014. Genetic analysis of a temperament test as a tool to select against everyday life fearfulness in Rough Collie. J. Anim. Sci. 92, 4843-4855.

Asher, L., Blythe, S., Roberts, R., Toothill, L., Craigon, P.J., Evans, K.M., Green, M.J., England, G.C.W., 2013. A standardized behavior test for potential guide dog puppies: Methods and association with subsequent success in guide dog training. J. Vet. Behav.: Clin. Appl. Res. 8, 431-438.

Babisch, W., 2003. Stress hormones in the research on cardiovascular effects of noise. Noise Health 5, 111.

Banis, S., Lorist, M.M., 2012. Acute noise stress impairs feedback processing Biol Psychology 91, 163171.

Batt, L.S., Batt, M.S., Baguley, J.A., McGreevy, P.D., 2008. Factors associated with success in guide dog training. J. Vet. Behav.: Clin. Appl. Res. 3,143-151.

Beerda, B., Schilder, M.B.H., van Hooff, J.A.R.A.M., de Vries, H.W., Mol, J.A., 1998. Behavioural, saliva cortisol and heart rate responses to different types of stimuli in dogs. Appl. Anim. Behav. Sci. 58, 365381.

Beerda, B., Schilder, M.B.H., van Hooff, J.A.R.A.M., de Vries, H.W., 1997. Manifestations of chronic and acute stress in dogs. Appl. Anim. Behav. Sci. 52, 307-319.

Blackshaw, J.K., Cook, G.E., Harding, P., Day, C., Bates, W., Rose, J., Bramham, D., 1990. Aversive responses of dogs to ultrasonic, sonic and flashing light units. Appl. Anim. Behav. Sci. 25, 1-8.

Blackwell, E.J., Bradshaw, J.W.S., Casey, R.A., 2013. Fear responses to noises in domestic dogs: Prevalence, risk factors and co-occurrence with other fear related behaviour. Appl. Anim. Behav. Sci. $145,15-25$.

Blanchard, R.J., Blanchard, D. C., 1969. Crouching as an index of fear. J. Comp. Physiol. Psychol. 67, 370375.

Bloom, T., Friedman, H., 2013. Classifying dogs' (Canis familiaris) facial expressions from photographs. Behav. Proc. 96, 1-10.

Branson, N.J., Rogers, L.J., 2006. Relationship between paw preference strength and noise phobia in Canis familiaris. J. Comp. Physiol. 120,176-183.

Breier, A., Albus, M., Pickar, D., Zahn, T.P., 1987. Controllable and uncontrollable stress in humans: alterations in mood and neuroendocrine and psychophysiological function. Am. J. Psychiatry 144, 1419-1425. 
Burghardt, W.F., Jr., 2013. Canine post-traumatic stress disorder in military working dogs. 2013 ACVB/AVSAB Veterinary Behavior Symposium Proceedings, pages 5-9, Chicago, IL.

Cao, X., Irwin, D.M., Liu, Y.-H., Cheng, L.-G., Wang, L., Wang., G.-D., Zhang, Y.-P., 2014. Balancing selection on $\mathrm{CDH} 2$ may be related to the behavioral features of the Belgian malinois. PLOS ONE 9(10): e110075. doi:10.1371/journal.pone.0110075.

Cottam, N., Dodman, N.h., Ha, J.C., 2013. The effectiveness of the Anxiety Wrap in the treatment of canine thunderstorm phobia: An open-label trial. J. Vet. Behav.: Clin. Appl. Res. 8, 154-161.

Cracknell, N.R., Mills, D.S., 2011. An evaluation of owner expectation on apparent treatment effect in a blinded comparison of 2 homeopathic remedies for firework noise sensitivity in dogs. J. Vet. Behav.: Clin. Appl. Res. 6:21-30.

Crowell-Davis, S., Seibert, L., Sung, W., Parthasarathy, V., Curtis, T., 2003. Use of clomipramine, alprazolam, and behavior modification for treatment of storm phobia in dogs. J. Am. Vet. Med. Assoc. $222,744-748$.

Dale, A.R., Walker, J.K., Farnworth, M.J., Morrissey, S.V., Waran, N.K., 2010. A survey of owners' perceptions of fear of fireworks in a sample of dogs and cats in New Zealand. N. Z. Vet. J. 58, 286-291.

Davis M., 1997 Neurobiology of fear responses: the role of the amygdala. J. Neuropsych. Clin. Neurosci. 9, 382-402.

De Meester, R.H., Pluijmakers, J., Vermeire, S., Laevens, H., 2011. The use of the socially acceptable behavior test in the study of the termperament of dogs. J. Vet. Behav.: Clin. Appl. Res. 6, 211-224.

Dodman, N.H., Karlsson, E.K., Moon-Fanelli, A., Galdzicka, M., Perloski, M., Shuster, L., Lindblad-Toh, K., Ginns E.I., 2010. A canine chromosome 7 locus confers compulsive disorder susceptibility. Mol. Psych. 15, 8-10.

Dodman, N.H., Ginns, E.I., Shuster, L., Moon-Fanelli, A.A., Galdzicka, M., Zheng, J., Ruhe, A.L., Neff, M.W., 2016. Genomic risk for severe canine compulsive disorder, a dog model of human OCD. Intern J Appl Res Vet Med. 14, 1-18.

Dreschel, N.A., 2010. The effects of fear and anxiety on health and lifespan in pet dogs. Appl. Anim. Behav. Sci. 125, 157-162.

Dreschel, N.A., Granger, D.A., 2005. Physiological and behavioral reactivity to stress in thunderstormphobic dogs and their caregivers, Appl. Anim. Behav. Sci. 95, 153-168.

Dykman, R.A., Murphree, O.D., Ackerman, P.T., 1966. Litter patterns in the offspring of nervous and stable dogs: II. Autonomic and motor conditioning. J. Nerv. Mental Dis. 141, 419-431.

Eraslan. E., Akyazi, I., Ergül-Ekiz, E., Matur,E., 2015. Noise stress-induced changes in mRNA levels of corticotropin-releasing hormone family molecules and glucocorticoid receptors in the rat brain. Folia Biol (Praha). 2015, 61, 66-73. 
Evans, K.M., Lewis, T.W., Asher, L., Blythe, S., Bottomley, M., Tootill, L., Roberts, R., Whiteside, H., England, G.W.C., Blott, S.C., 2015. Genetic evaluation of traits in a standardized behavioral test for potential guide dog puppies using crossbreed models. J. Vet. Behav.: Clin. Appl. Res. 10, 459-464.

Folmer, R.L., Billings, C.J., Diedesch-Rouse, A.C., Gallun, F.J. and Lew, H.L., 2011. Electrophysiological assessments of cognition and sensory processing in TBI: Applications for diagnosis, prognosis and rehabilitation. Int. J. Psychophys. , 82, 4-15.

Foyer, P., Bjällerhag, N., Wilsson, E., Jensen, P., 2014. Behaviour and experiences of dogs during the first year of life predict the outcome in a later temperament test. Appl Anim. Behav. Sci. 155, 93-100.

Foyer, P. Svedberg, A.-M., Nilsson, E., Wilsson, E., Faresjö, Å., Jensen, P., 2015. Behavior and cortisol responses of dogs evaluated in a standardized temperament test for military working dogs. J. Vet. Behav.: Clin. Appl. Res. 11,7-12.

Francks, C., Maegawa, S., Lauren, J., Abrahams, B.S., Velayos-Baeza, A.., Medland, S.E., Colella, S., Groszer, M., McAuley, E.Z., Caffrey, T.M., Timmusk, T., Pruunsild, P., Koppel, I., Lind, P.A., MatsumotoItaba, N., Nicod, J., Xiong, L., Joober, R., Enard, W., Krinsky, B., Nanba, E., Richardson, A.J., Riley, B.P., Martin, N.G., Strittmatter, S.M., Möller, H.-J., Rujescu, D., St. Clair, D., Muglia, P., Roos, J.L., Fisher, S.E., Wade-Martins, R., Rouleau, G.A., Stein, J.F., Karayiorgou, M., Geschwind, D.H., Ragoussis, J., Kendler, K.S., Airaksinen, M.S., Oshimura, M., DeLisi, L.E., Monaco, A.p., 2007. LRRTM1 on chromosome 2p12 is a maternally suppressed gene that is associated paternally with handedness and schizophrenia. Mol. Psych. 2007:1-11. doi:10.1038/sj.mp.4002053.

Gazzano, A., Mariti, C., Sighieri, C., Ducci, M., Ciceroni, C., McBride, E.A., 2007. Survey of undesirable behaviors displayed by potential guide dogs with puppy walkers. J. Vet. Behav.: Clin. Appl. Res. 3, 104113.

Gruen ME, Sherman BL, 2008. Use of trazodone as an adjunctive agent in the treatment of canine anxiety disorders: 56 cases (1995-1997). J. Am. Vet. Med. Assoc. 233, 1902-1907.

Haghighi, M., Jahangard, L., Mohammad-Beigi, H., Bajoghli, H., Hafezian, H., Rahimi, A., Afshar, H., Holsboer-Trachsler, E., Brand, S., 2013. In a double-blind, randomized and placebo-controlled trial, adjuvant memantine improved symptoms in inpatients suffering from refractory obsessive-compulsive disorders (OCD). Psychopharmacology 228, 633-640.

Hammerle, M., Horst, C., Levine, E., Overall, K., Radosta, L., Rafter-Ritchie, M., Yin, S., 2015. 2015 AAHA Canine and Feline Behavior Management Guidelines. J. Am. Anim. Hosp. Assoc. 51, 205-221.

Harvey, N.D., Craigon, P.J., Sommerville, R., McMillan, C., Green, M., England, G.C.W., Asher, L., 2015. Test-retest reliability and predictive validity of a juvenile guide dog behavior test. J. Vet. Behav.: Clin. Appl. Res. 11, 65-76.

Harvey, N.D., Craigon, P.J., Blythe, S.A., England, G.C.W., Asher, L., 2016. Social rearing environment influences dog behavioral development. J. Vet. Behav.: Clin. Appl. Res., this issue.

Haverbeke, A., Laporte, B., Depiereux, E., Giffoy, J.-M., Diederich, C., 2008. Training methods of military dog handlers and their effects on the team's performances. Appl. Anim. Behav. Sci. 113, 110-122. 
Hydbring-Sandberg, E., von Walter, L.W., Höglund, K., Svartberg, K., Swenson, L., Forkman, B., 2004. Physiological reactions to fear provocation in dogs. J. Endocrinol. 180, 439-448.

Hsu, Y., Serpell, J.A., 2003. Development and validation of a questionnaire for measuring behavior and temperament traits in pet dogs. J. Am. Vet. Med. Assoc. 223,1293-1300.

Jasnow, A.M., Lynch, J.F., Gilman, T.L., Riccio, D.C., 2016. Perspectives on fear generalization and its implications for emotional disorders. J Neurosci Res. doi: 10.1002/jnr.23837.

Kerestes, R., Davey, C.G., Stephanoua, K., Whittle, S., Harrison, B.J., 2014. Functional brain imaging studies of youth depression: A systematic review Neuroimage: Clinical 4, 209-231.

King, T., Hemsworth, P.H., Coleman, G.J., 2003. Fear of novel and startling stimuli in domestic dogs. Appl. Anim. Behav. Sci. 82, 45.

Kuhne, F., Hößler, J., Struwe, R., 2012a. Affective behavioural responses by dogs to tactile human-dog interactions. Berl. Munch. Tierarzt. Wochenschr. 125, 371-378.

Kuhne, F., Hößler, J.C., Struwe, R., 2012b. Effects of human-dog familiarity on dogs' behavioural responses to petting. Appl. Anim. Behav. Sci. 142, 176-181.

Kuhne, F., Hößler, J.C., Struwe, R., 2014.Behavioral and cardiac responses by dogs to physical humanedog contact. J. Vet. Behav.: Clin. Appl. Res. 9, 93-97.

LeDoux, J.E., 2000. Emotion circuits in the brain. Annu. Rev. Neurosci. 23, 155-184.

LeDoux, J.E., Iwata, J., Cicchetti, P., Reis,D.J., 1988. Different projections of the central amygdaloid nucleus mediate autonomic and behavioral correlates of conditioned fear. J. Neurosci. 8(7), 2517- 2529.

Ley, J., Coleman, G.J., Holmes, R., Hemsworth, P.H., 2007. Assessing fear of novel and startling stimuli in domestic dogs. Appl. Anim. Behav. Sci. 104, 71-84.

Mariti, C., Gazzano, A., Moore, J.L., Baragli, P., Chelli, L., Sighieri, C., 2012. Perception of dogs' stress by their owners. J. Vet. Behav.: Clin. Appl. Res. 7, 213-219.

McCobb, E.C., Brown E., Damiani, K., Dodman, N., 2001. Thunderstorm phobia in dogs: An internet survey of 69 cases. J Am. Anim. Hosp. Assoc. 37, 319-324.

Moon-Fanelli, A.A., Dodman, N.H., 1998. Description and development of compulsive tail chasing in terriers and response to clomipramine treatment. J. Am. Vet. Med. Assoc. 212, 1252-7.

Moon-Fanelli, A.A., Dodman, N.H., Cottam, N., 2007. Blanket and flank sucking in Doberman Pinschers. J. Am. Vet. Med. Assoc. 231,907-912.

Murphree, O.D., Dykman, R.A., Peters, J.E., 1967 Genetically-determined abnormal behavior in dogs: results of behavioral tests. Cond. Reflex 2, 199-205. 
Nasca, C., Zelli, D., Bigio, B., Piccinin, S., Scaccianoce, S., Nistico, R., McEwen, B.S., 2015. Stress dynamically regulates behavior and glutamatergic gene expression in hippocampus by opening a window of epigenetic plasticity. PNAS 112(48) 14960-14965. doi: 10.1038/nn.3778.

Ogata, N., Gillis, T.E., Liu, X., Cunningham, S.M., Lowen, S.B., Adams, B.L., Sutherland-Smith, J., Mintzopoulos, D., Janes, A.C., Dodman, N.H., Kaufman, M.J., 2013. Brain structural abnormalities in Doberman pinschers with canine compulsive disorder. Prog Neuropsychopharmacol Biol Psychiatry 45, 1-6.

O’Neill, D.G., Church, D.B., McGreevy, P.D., Thomson, P.C., Brodbelt, D.C., 2013. Longevity and mortality of owned dogs in England. Vet. J. 198, 638-643.

Overall, K.L., 2000. Dogs as "natural" models of human psychiatric disorders: assessing validity and understanding mechanism. Prog. Neuropsychopharmacol. Biol. Psychiatry 24, 727-276.

Overall, K.L., 2003. The ethogram project. J. Vet. Behav.: Clin. Appl. Res. 9, 1-5.

Overall, K.L., 2003. Watching behavior: Normal, abnormal, and ethograms. J. Vet. Behav.: Clin. Appl. Res. 9, 47-49.

Overall, K.L., 2013. Manual of Clinical Behavioral Medicine. Elsevier, St. Louis.

Overall, K.L., Dunham, A.E., Frank, D., 2001. Frequency of nonspecific clinical signs in dogs with separation anxiety, thunderstorm phobia, and noise phobia, alone or in combination. J. Am. Vet. Med. Assoc. 219, 467-473.

Overall, K.L., Crowell-Davis, S.L., Dehasse, J., Fatjó, J., Houpt, K.A., Mills, D.S., Palestrini, C., Beata, C., Seksel, K., 2006. Terminology think tank. J. Vet. Behav.:Clin. Appl. Res. 1(1, 2, 3):29-46. 80-83, 121-123.

Overall, K.L., Hamilton, S.P., Chang, M.L., 2006. Understanding the genetic basis of canine anxiety: phenotyping dogs for behavioral, neurochemical, and genetic assessment. J. Vet. Behav.: Clin. Appl. Res. $1,124-141$.

Overall, K.L., Tiira, K., Broach, D., Bryant, D., 2014. Genetics and behavior: A guide for practitioners. Vet. Clin. NA: Sm. Anim. Pract. 44, 483-505.

Popoli, M.L., Yan, Z., McEwen, B.S., Sanacora, G., 2011. The stressed synapse: the impact of stress and glucocorticoids on glutamate transmission. Nature Rev. Neurosci. 13(1):22-37. doi: 10.1038/nrn3138.

R Core Team, 2016. R: A language and environment for statistical computing. R Foundation for Statistical Computing, Vienna, Austria. URL http://www.R-project.org/.

Rogerson, T., Jayaprakash, B., Cai, D.J., Sano, Y.,, Lee, Y.-S., Zhou, P., Deiseeroth, K., Silva, A.J., 2016. Molecular and cellular mechanisms for trapping and activating emotional memories. PLoS One. 2016 11(8):e0161655. doi: 10.1371/journal.pone.0161655 
Schilder, M.B.H., van der Borg, J.A.M., 2004. Training dogs with the help of the shock collar: short and long term behavioural effects. Appl. Anim. Behav. Sci. 85, 319-334.

Sherman, B.L., Mills, D.S., 2008. Canine anxieties and phobias: an update on separation anxiety and noise aversions. Vet. Clin. NA: Sm. Anim. Pract.38, 1081-106.

Sherman, B.L., Gruen, M.E., Case, B.C., Foster, M.L., Fish, R.E., Lazarowski, L., DePuy, V., Dorman, D.C., 2014. A test for the evaluation of emotional reactivity in Labrador retrievers used for explosives detection. J. Vet. Behav.: Clin. Appl. Res. 10, 94-102.

Shull-Selcer, E.A., Stagg, W., 1991. Advances in understanding and treatment of noise phobias. Vert. Clin. NA: Sm. Anim. Pract. 21, 353-367.

Siniscalchi, M., Quaranta, A., Rogers, L.J., 2008. Hemispheric specialization in dogs for processing different acoustic stimuli. PLoS ONE 3, e3349 doi:10.1371/journal.pone.0003349.

Siniscalchi, M., McFarlane, J.R., Kauter, K.G., Quaranta, A., Rogers, L.J., 2013. Cortisol levels in hair reflect behavioural reactivity of dogs to acoustic stimuli. Res. Vet. Sci. 94, 49-54.

Stone, H.R., McGreevy, P.D., Starling, M.J., Forkman, B., 2016. Associations between domestic-dog morphology and behavior scores in the Dog Mentality Assessment. PLoS ONE 11(2): e0149403. doi:10.1371/journal.pone.0149403

Storengen, L.M., Lingaas, F., 2015. Noise sensitivity in 17 dog breeds: Prevalence, breed risk and correlation with fear in other situations, Appl. Anim. Behav. Sci. 171, 152-160.

Tami, G. Gallagher, A., 2009. Description of the behavior of domestic dog (Canis familiaris) by experienced and inexperienced people. Appl Anim. Behav. Sci. 120, 159-169.

Temesi, A., Turcsán, B., Miklósi, A., 2014. Measuring fear in dogs by questionnaires: An exploratory study toward a standardized inventory. Appl. Anim. Behav. Sci. 161, 121-130.

Tiira, K., Hakosalo, O., Kareinen, L., Thomas, A., Hielm-Björkman, A., Escriou, C. Arnold, P. Lohi, H.2012. Environmental effects on compulsive tail chasing in dogs. PLoS ONE 7(7): e41684.

doi:10.1371/journal.pone.0041684

Tiira, K., Lohi, H., 2014. Reliability and validity of a questionnaire survey in canine anxiety research. Appl. Anim. Behav. Sci. 155, 82-92.

Tiira, K., Lohi, H., 2015. Early life experiences and exercise associate with canine anxieties. PLoS ONE 10(11): e0141907. doi:10.1371/journal.pone.0141907.

Tiira, K., Sulkama, S., Lohi, H., 2016. Prevalence, comorbidity and behavioral variation in canine anxiety J. Vet. Behav.: Clin. Appl. Res. This issue.

Tomkins, L.M., Thomson, P.C., McGreevy, P.D., 2011. Behavioral and physiological predictors of guide dog success. J. Vet. Behav.: Clin. Appl. Res. 6,178-187. 
Tomkins, LM, Thomson, PC, McGreevy, PD., 2012. Associations between motor, sensory and structural lateralisation and guide dog success. Vet. J. 192, 359-367.

Tully, K., Bolshakov, V.Y., 2010. Emotional enhancement of memory: How norepinephrine enables synaptic plasticity. Mol. Brain 3,15._DOI: 10.1186/1756-6606-3-15

van Rooy D., Arnot, E.R., Early, J.B., McGreevy, P., Wade, C.W., 2014. Holding back the genes: limitations of research into canine behavioural genetics. Canine Genetics Epidemiol. 1,7. doi:10.1186/2052-6687-1-7

Vermeire, S., Audenaert, K., De Meester, R., Vandermeulen, E., Waelbers, T., De Spiegeleer, B., Eersels, J., Dobbeleir, A., Peremans, K., 2012. Serotonin 2A receptor, serotonin transporter and dopamine transporter alterations in dogs with compulsive behaviour as a promising model for human obsessive compulsive disorder. Psychiatry Res.201, 78-87.

Vonholdt, B.M., Pollinger, J.P., Lohmueller, K.E., Han, E., Parker, H.G., Quignon, P., Degenhardt, J.D., Boyko, A.R., Earl, D.A., Auton, A., Reynolds, A., Bryc, K., Brisbin, A., Knowles, J.C., Mosher, D.S., Spady, T.C., Elkahloun, A., Geffen, E., Pilot, M., Jedrzejewski, W., Greco, C., Randi, E., Bannasch, D., Wilton, A., Shearman, J., Musiani, M., Cargill, M., Jones, P.G., Qian, Z., Huang, W., Ding, Z.L., Zhang, Y.P., Bustamante, C.D., Ostrander, E.A., Novembre, J., Wayne, R.K., 2010. Genome-wide SNP and haplotype analyses reveal a rich history underlying dog domestication. Nature 464, 898-902.

Wan, M., Bolger, N., Champagne, F.A., 2012. Human perception of fear in dogs varies according to experience with dogs. PLoS ONE 7(12): e51775. doi:10.1371/journal.pone.0051775.

Whitaker, K.J., Vértes,P.E., Romero-Garcia, R., Váša, F., Moutoussis, M., Prabhu, G., Weiskopf, N., Callaghan, M.F., Wagstyl, K., Rittman, T., Tait, R., Ooi, C., Suckling, J., Inkster, B., Fonagy, F., Dolan, R.J., Jones, P.B., Goodyer, I.M., the NSPN Consortium, Bullmore, E.T., 2016. Adolescence is associated with genomically patterned consolidation of the hubs of the human brain connectome. PNAS 113, 91059110.

Yokoyama, J.S., 2010. Investigation of complex neuropsychiatric disorders in the domestic dog: genomewide surveys for loci underlying noise phobia and adult-onset deafness in purpose-bred dogs. PhD Thesis. San Francisco: University of California. 


$$
\text { 달 }
$$


Figure 2: Frequency of reported reaction score categories by breed and stimulus. N=81, BOC; 59, AUS; 58 , GSD. Score distributions for all breeds are significantly different. Randomization tests, all $P<0.05$.
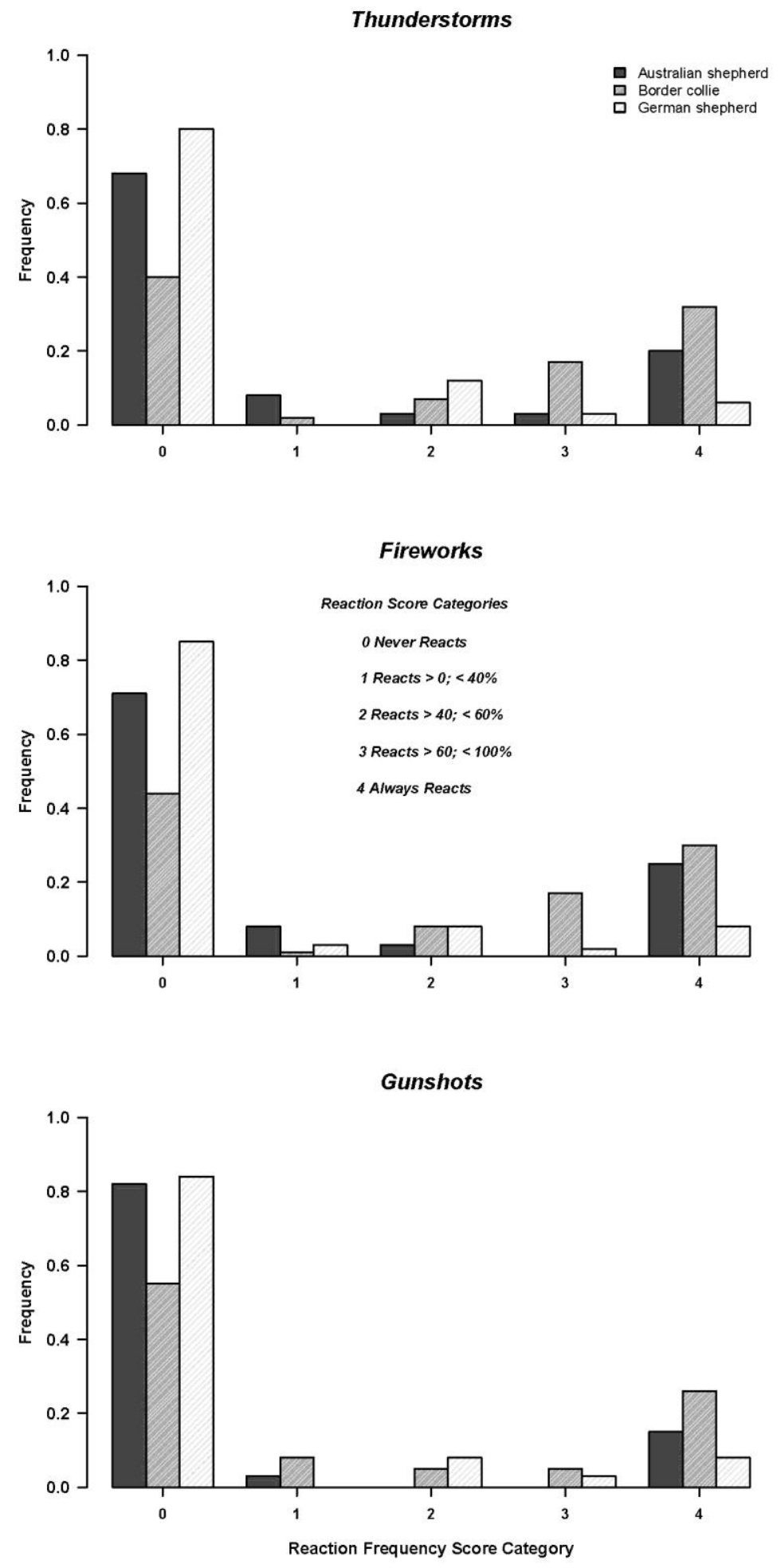
Figure 3: Age frequency distribution by breed; $A U S=A$ ustralian shepherd; $B O C=B o r d e r$ collie; $\mathrm{GSD}=$ German shepherd; note differences in $\mathrm{Y}$ axis by breed. Mean ages differ significantly among breeds (ANOVA, $F=15.62, \mathrm{df}=2,195, P<5.08 \mathrm{e}-7$ ). Post-hoc comparison tests (Tukey's HSD) reveal significant differences among all pairwise comparisons except AUS - GSD ( $\left.P_{\text {adj }}=0.096\right)$. Border collies differ significantly from both AUS $\left(P_{\text {adj }}<0.004\right)$ and GSD $\left(P_{\text {adj }}=0.04 e-5\right)$.
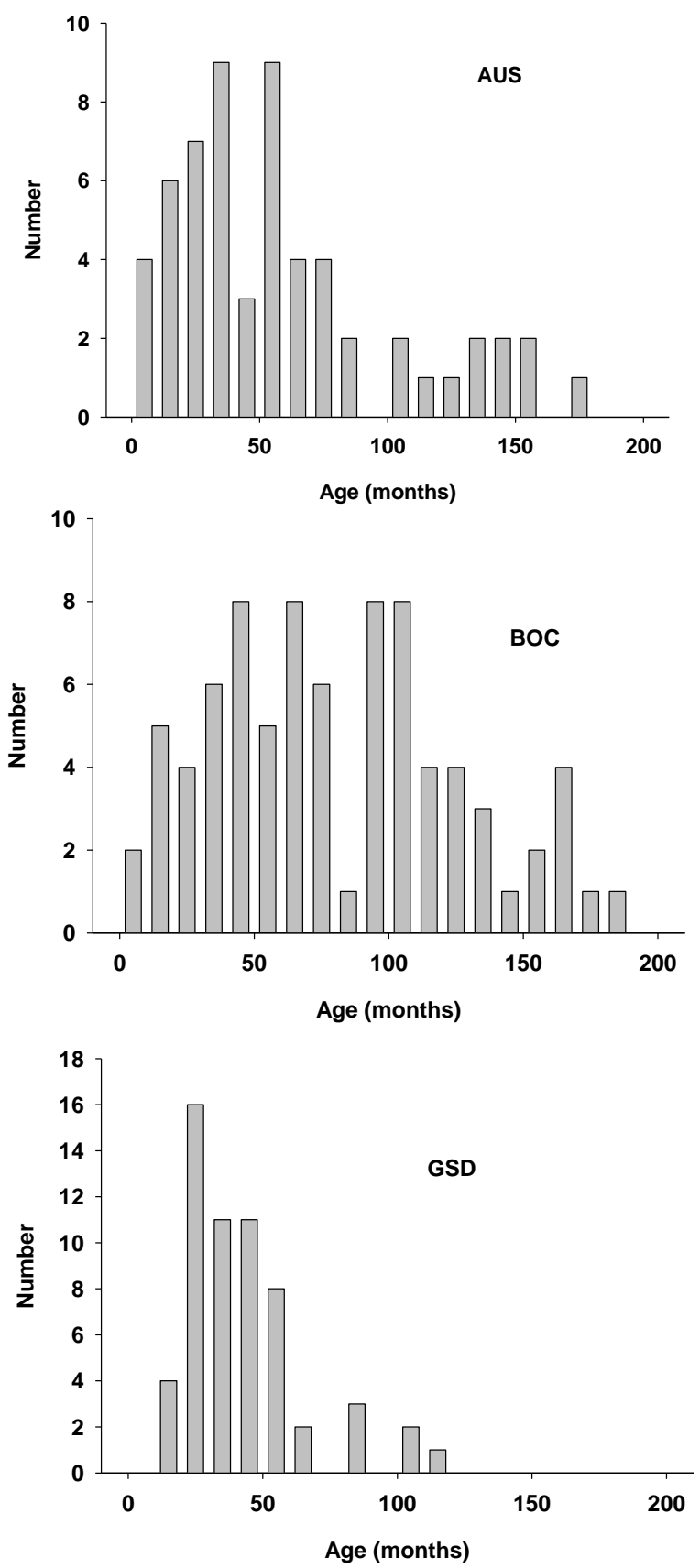
Figure 4: Linear regressions of AIR score on age for affected dogs of each breed; note differences in $Y$ axis for GSD. AUS: $F=1.315, \mathrm{df}=1,25, P>0.262, \mathrm{r}^{2}$ adj $=0.12$. BOC: $\mathrm{F}=1.387, \mathrm{df}=1,47, P>0.244, \mathrm{r}^{2}{ }_{\text {adj }}$ $=0.008$. GSD: $F=11.69, \mathrm{df}=1,13, P<0005, \mathrm{r}^{2}$ adj $=0.433$.
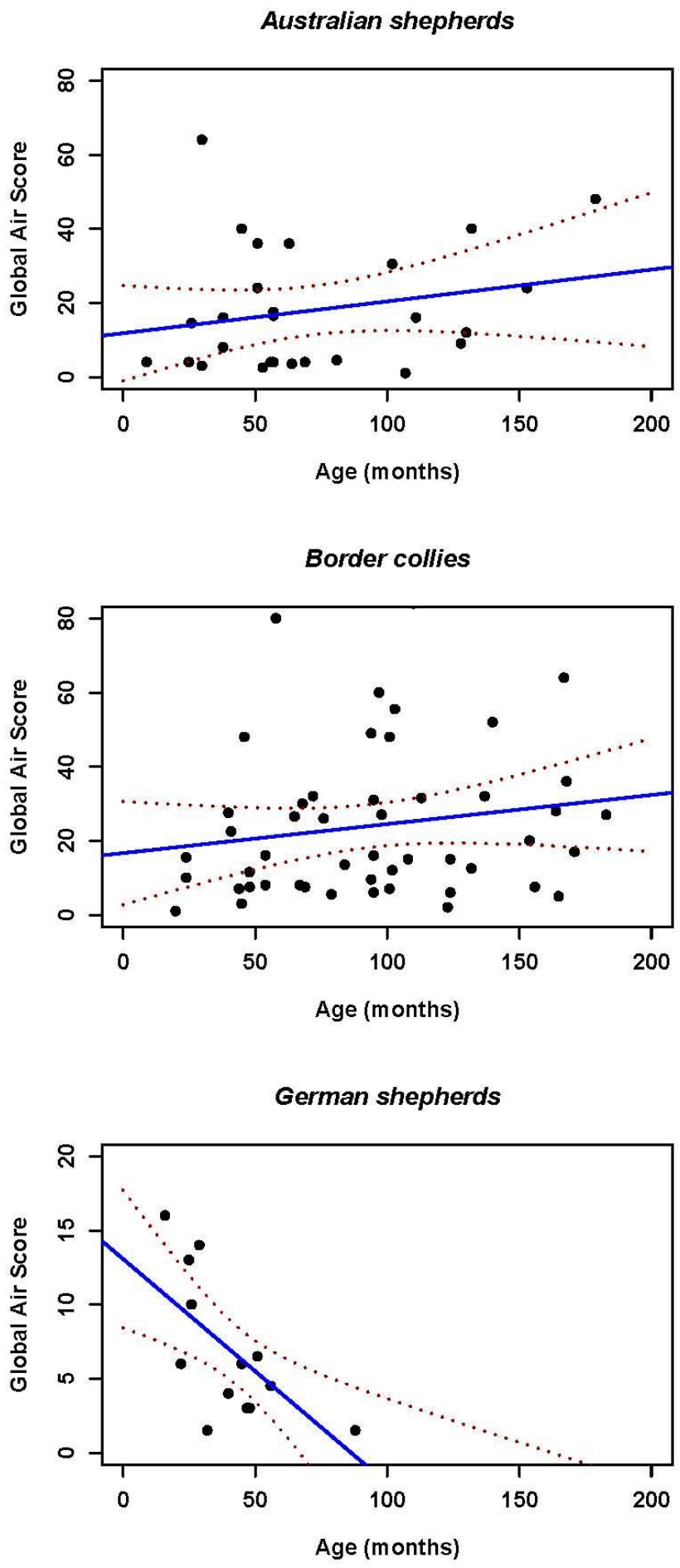
Figure 5: Number of signs as a function of stimulus $x$ age; AUS=Australian shepherd; BOC=Border collie; $G S D=G e r m a n$ shepherd; note that the scales for the $X$ and $Y$ axes vary by breed and condition. ). For AUS: thunderstorms: $(\mathrm{F}=0.184, \mathrm{df}=1,17, P>0.67)$, fireworks: $(\mathrm{F}=0.850, \mathrm{df}=1,19, P>0.369)$, gunshots: $(\mathrm{F}=0.203, \mathrm{df}=1,9, P>0.66)$. For BOC: thunderstorms: $(\mathrm{F}=4.01, \mathrm{df}=1,44, P>0.051)$, fireworks: $(\mathrm{F}$ $=0.748, \mathrm{df}=1,40, P>0.392)$, gunshots: $(\mathrm{F}=0.064, \mathrm{df}=1,30, P>0.80)$. Regression analysis on the German shepherd data cannot be done due to lack of variation in the dependent variable.
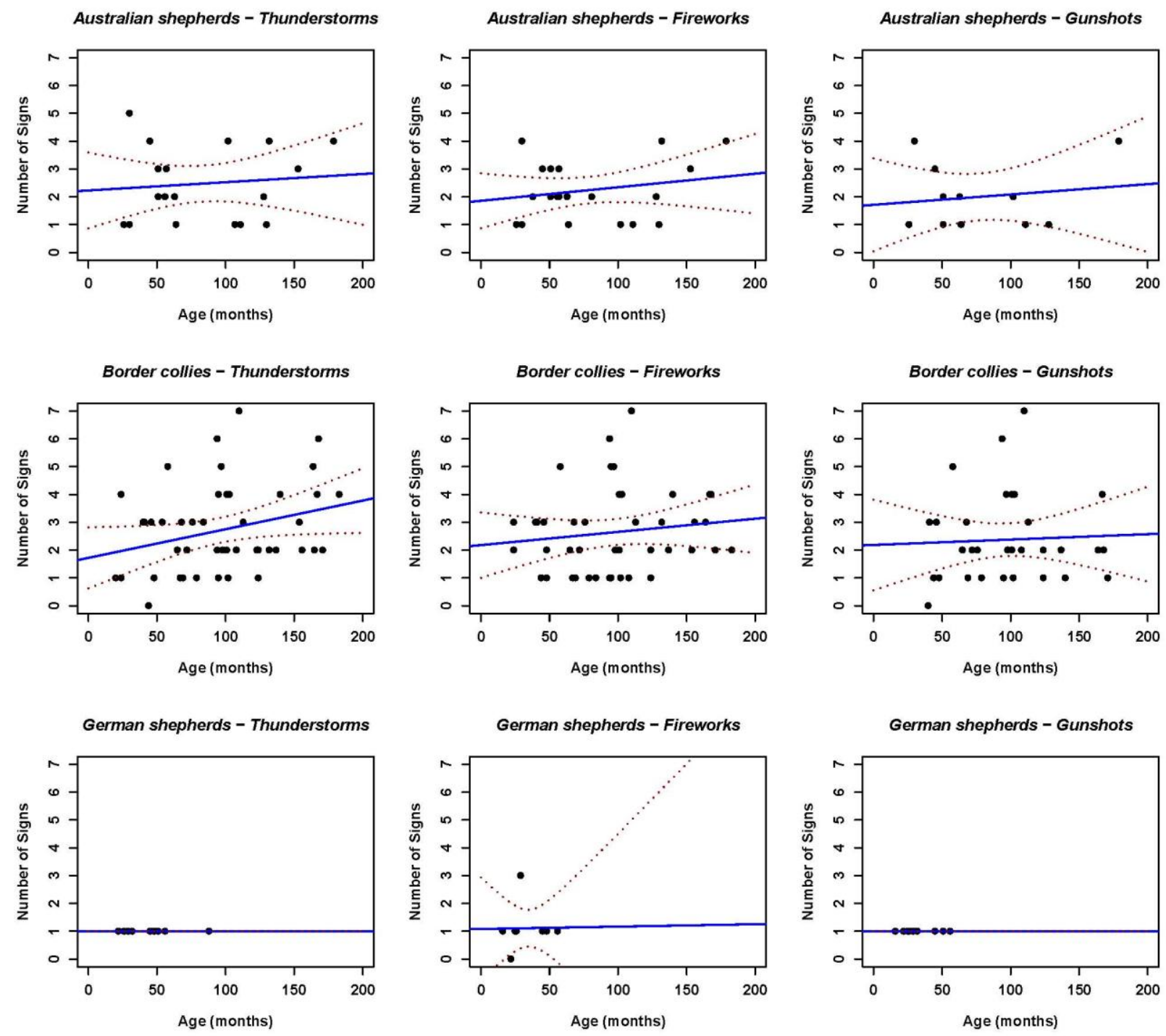
Figure 6: Relative frequencies of signs, given breed and provocative stimulus; $A U S=A u s t r a l i a n$ shepherd; $\mathrm{BOC}=$ Border collie; GSD=German shepherd; Conditions: F=fireworks; T=thunderstorms; $\mathrm{G}=$ guns; Signs: $\mathrm{S}=$ salivate, $\mathrm{E}=$ escape, $\mathrm{H}=$ hide, $\mathrm{T}=$ tremble, $\mathrm{V}=$ vocalize, $\mathrm{P}=$ pace, $\mathrm{F}=$ freeze, $\mathrm{N}=$ pant.

| Behaviors not engaged in are not represented. Pairwise permutation tests indicate that the distribution of signs for GSD differ significantly from those of both AUS $(P<0.0001)$ and BOC $(P<0.0001)$. The distribution of signs of AUS and BOC do not differ significantly from each other $(P>0.45)$.

Relative Frequencies of Signs
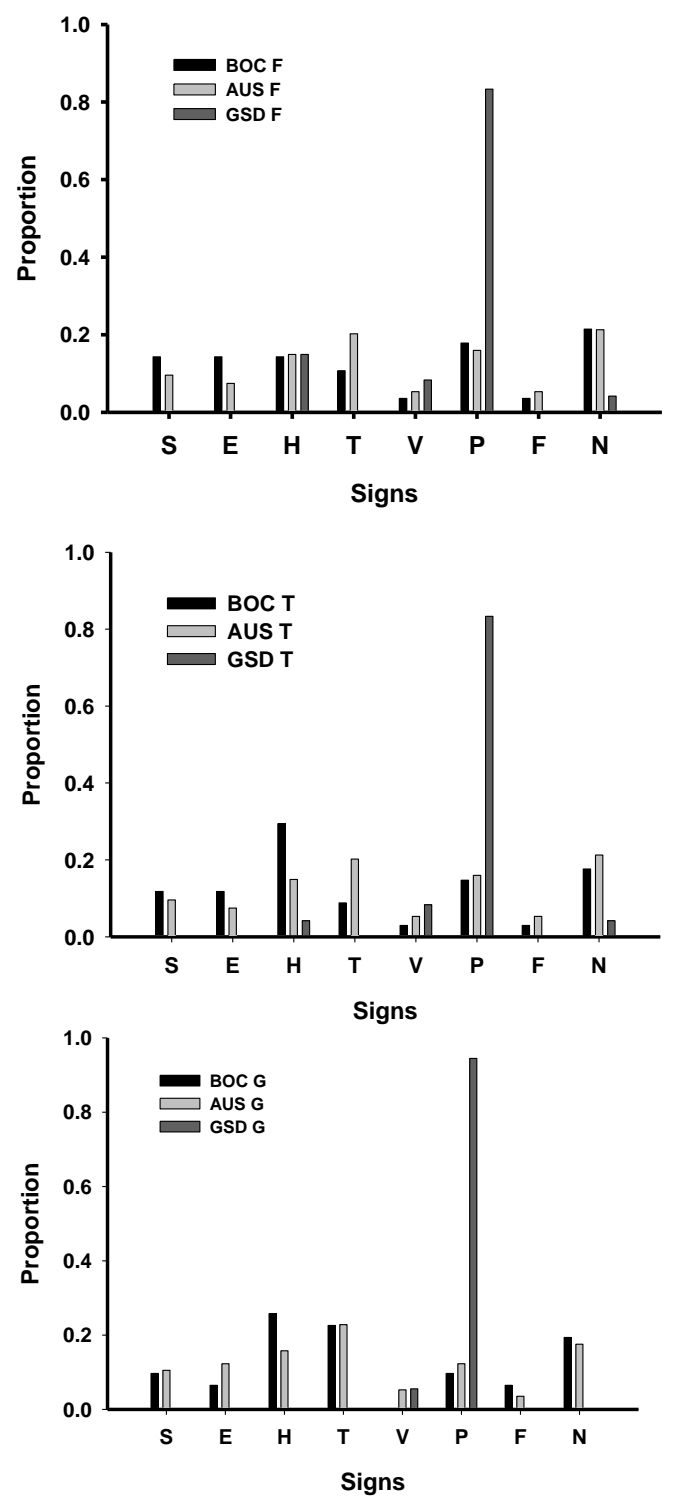
Figure 7: Underlying genetic substructure between BOC (predominantly in green) and AUS (predominantly yellow \&/or blue) with $\mathrm{k}=2$ and 3 . Each dog is represented as one bar; $\mathrm{k}$ represents the number of putative number of underlying assumed groups within the entire sample group (Overall and Hamilton, unpublished).

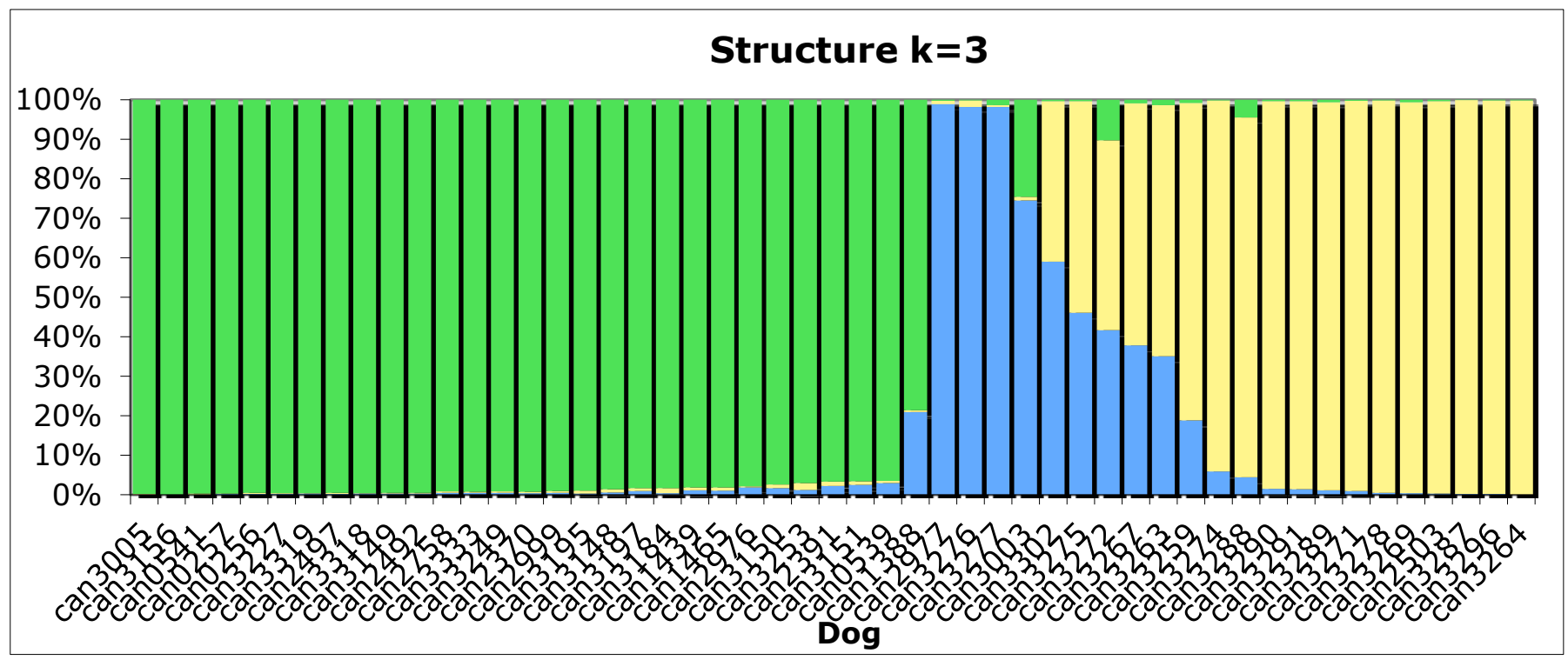




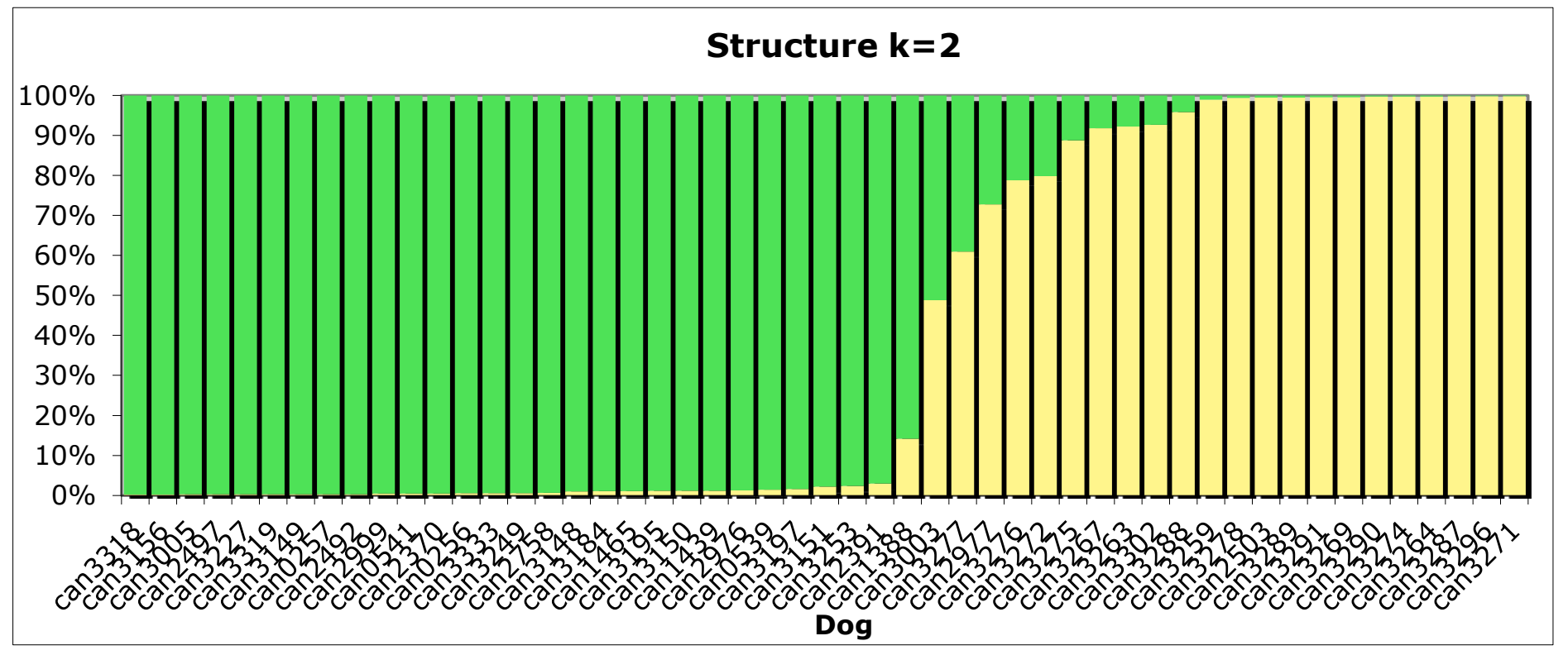


Table 1: Age data by breed; AUS=Australian shepherd; BOC=Border collie; GSD=German shepherd; $\mathrm{SE}=$ standard error; $\mathrm{Cl}=$ confidence interval . All pairwise comparisons for means significantly different (Welch's t-test; all $P<0.0001$ ). Significance levels estimated by permutation tests using 10,000 permutations per test. All pairwise comparisons for medians are significantly different (Wilcoxon Rank Sum Tests; all $P<0.05)$.

\begin{tabular}{|l|l|l|l|l|c|}
\hline & $\mathrm{N}$ & $\begin{array}{l}\text { mean } \\
\text { (months) }\end{array}$ & SE & $95 \% \mathrm{Cl}$ & median \\
\cline { 2 - 6 } & 59 & 58.00 & 5.60 & 11.21 & 50 \\
\hline BUS & 81 & 79.95 & 5.01 & 9.98 & 72 \\
\hline GSD & 58 & 42.85 & 3.07 & 6.14 & 37 \\
\hline
\end{tabular}


Table 2: AIR score data for affected dogs (non-zero AIR score) by breed; AUS=Australian shepherd; $\mathrm{BOC}=$ Border collie; GSD=German shepherd; $\mathrm{SD}=$ standard deviation; $\mathrm{SE}=$ standard error; Max=highest AIR score; Min=lowest AIR score. Mean AIR scores for AUS and BOC are not significantly different $(t=1.73$, $\mathrm{df}=60.87, P>0.0839)$, but both are significantly different from those of GSD (AUS - GSD: $\mathrm{t}=3.48, \mathrm{df}=$ $32.48, P<0.0015$; BOC- GSD: $\mathrm{t}=6.51, \mathrm{df}=67.76, P<1 \mathrm{e}-08)$.

\begin{tabular}{|l|l|l|l|}
\hline & AUS & BOC & GSD \\
\hline $\mathrm{N}$ & 27 & 55 & 16 \\
\hline Mean & 18.02 & 25.25 & 6.13 \\
\hline SD & 16.67 & 19.94 & 4.72 \\
\cline { 2 - 4 } SE & 3.21 & 2.69 & 1.18 \\
\hline Max & 64 & 84 & 16 \\
\hline Min & 1 & 1 & 1.5 \\
\hline
\end{tabular}


Table 3: Co-occurrence of signs related to noise reactivity. This table presents the Spearman rank correlation of individuals that react to the stimulus in the first column to reaction to the other stimuli (listed in the other three columns). $* * * * P<0.0001, * * * p<0.001, * * p<0.01$.

\begin{tabular}{|l|l|l|l|}
\hline AUS [N] & Thunderstorms & Fireworks & Gunshots \\
\hline Thunderstorms & 1.000 & $0.896^{* * * *}[59]$ & $0.685^{* * * *}[59]$ \\
\hline Fireworks & $0.759^{* * *}[21]$ & 1.000 & $0.753^{* * * *}[59]$ \\
\hline Gunshots & $0.678^{* * *}[21]$ & $0.478^{*}[21]$ & 1.000 \\
\hline
\end{tabular}

\begin{tabular}{|l|l|l|l|}
\hline BOC [N] & Thunderstorms & Fireworks & Gunshots \\
\hline Thunderstorms & 1.000 & $0.885^{* * * *}[87]$ & $0.717^{* * * *}[87]$ \\
\hline Fireworks & $0.608^{* * *}[53]$ & 1.000 & $0.842^{* * * *}[87]$ \\
\cline { 2 - 4 } & $0.394^{* *}[53]$ & $0.678^{* * *}[53]$ & 1.000 \\
\hline
\end{tabular}

\begin{tabular}{|l|l|l|l|}
\hline GSD [N] & Thunderstorms & Fireworks & Gunshots \\
\hline Thunderstorms & 1.000 & $0.860^{* * * *}[59]$ & $0.697^{* * * *}[59]$ \\
\hline Fireworks & $0.460^{* *}[14]$ & 1.000 & $0.805^{* * * *}[59]$ \\
\hline Gunshots & --- & -- & 1.000 \\
\hline
\end{tabular}


Table 4: Co-morbidity data by breed and provocative stimulus showing conditional probabilities of having co-morbid conditions. Pairwise permutation tests indicate all conditional probabilities are significantly greater than 0.7 or higher with all $P<0.001$.

\begin{tabular}{|c|c|c|c|}
\hline $\begin{array}{l}\text { Given that you } \\
\text { react to this }\end{array}$ & Conditional prob & $\begin{array}{l}\text { ility of reactin } \\
\text { stimuli }\end{array}$ & o these other \\
\hline AUS & Thunderstorms & Fireworks & Gunshots \\
\hline Thunderstorms & ----- & $0.95(19 / 20)$ & $0.75(12 / 20)$ \\
\hline Fireworks & $0.86(19 / 22)$ & ----- & $0.71(12 / 17)$ \\
\hline Guns & $1.00(12 / 12)$ & $1.00(12 / 12)$ & ----- \\
\hline BOC & Thunderstorms & Fireworks & Gunshots \\
\hline Thunderstorms & ----- & $0.96(48 / 50)$ & $0.84(38 / 45)$ \\
\hline Fireworks & $0.98(48 / 49)$ & ----- & $0.91(41 / 45)$ \\
\hline Guns & $0.97(37 / 38)$ & $1.00(38 / 38)$ & ----- \\
\hline GSD & Thunderstorms & Fireworks & Gunshots \\
\hline Thunderstorms & ---- & $0.69(9 / 13)$ & $0.69(9 / 13)$ \\
\hline Fireworks & $1.00(9 / 9)$ & ----- & $0.89(8 / 9)$ \\
\hline Guns & $0.89(8 / 9)$ & $0.78(7 / 9)$ & ----- \\
\hline
\end{tabular}

